\title{
Mechanistic studies of perfluorooctane sulfonate, perfluorooctanoic acid uptake by maize (Zea mays L. cv. TY2)
}

\author{
Bei Wen • Longfei Li • Yu Liu • Hongna Zhang • \\ Xiaoyu Hu • Xiao-quan Shan • Shuzhen Zhang
}

Received: 24 October 2012 / Accepted: 4 February 2013 /Published online: 17 February 2013

(C) Springer Science+Business Media Dordrecht 2013

\begin{abstract}
Background and aims Perfluorinated compounds (PFCs) are of particular environmental concern. The migration of PFCs from soil to plants is a likely pathway for PFCs to enter the human food chain. This study aimed to investigate the uptake mechanisms of perfluorooctane sulfonate (PFOS) and perfluorooctanoic acid (PFOA) by maize (Zea mays L. cv. TY2).
\end{abstract}

Responsible Editor: Juan Barcelo.

B. Wen $(\bowtie) \cdot$ L. Li $\cdot$ Y. Liu $\cdot$ H. Zhang $\cdot$ X.-q. Shan $\cdot$

S. Zhang

State Key Laboratory of Environmental Chemistry and Ecotoxicology, Research Center for Eco-Environmental

Sciences, Chinese Academy of Sciences,

Beijing 100085, China

e-mail: bwen@rcees.ac.cn

L. Li

e-mail: lilongfei491@126.com

Y. Liu

e-mail: yuliuism@gmail.com

H. Zhang

e-mail: zhanghongna.316@163.com

X.-q. Shan

e-mail: xiaoquan@rcees.ac.cn

S. Zhang

e-mail: szzhang@rcees.ac.cn

X. Hu

Beijing Center for Disease Prevention and Control,

Beijing 100031, China

e-mail: huxiaoyucn@yahoo.cn
Methods Hydroponic greenhouse experiments were performed.

Results The kinetics of PFOS and PFOA uptake fitted Mechaelis-Menten equation well, suggesting their carrier-mediated influx processes. Uptake of PFOS was insensitive to metabolic inhibitors $\left(\mathrm{NaN}_{3}\right.$ and $\mathrm{Na}_{3} \mathrm{VO}_{4}$ ). In contrast, treated with $\mathrm{NaN}_{3}$ and $\mathrm{Na}_{3} \mathrm{VO}_{4}$ reduced the uptake of PFOA by 83 and $43 \%$ respectively. PFOS uptake was decreased by $31 \%$ and $25 \%$ when plants were treated with aquaporin inhibitors, $\mathrm{AgNO}_{3}$ and glycerol, respectively, while aquaporin inhibitors had no effect on PFOA uptake. Anion channel blockers, 4, 4'-diisothiocyanostibene-2,2'-disolfonate (DID) and 5-nitro 2-(3-phenylpropylamine) benzoic acid (NPPB) inhibited the uptake of PFOS by $33 \%$ and $30 \%$, respectively. Anion channel blocker anthracene9-carboxylic acid (9-AC) decreased the uptake of PFOA by $28 \%$. No competitive uptake was found between PFOS and PFOA.

Conclusions Uptake of PFOS and PFOA by maize may have different mechanisms.

Keywords Perfluorooctane sulfonate $\cdot$ Perfluorooctanoic acid $\cdot$ Uptake $\cdot$ Mechanisms $\cdot$ Maize (Zea mays)

\section{Introduction}

Perfluorinated compounds (PFCs), especially perfluorooctanic sulfonic (PFOS) and perfluorooctanic acid (PFOA), are a class of widely used, persistent and bioaccumulative contaminants that are ubiquitous 
in the environment (Houde et al. 2006). They have been manufactured for more than 50 years, and are employed in a variety of industry and households. Many PFCs are resistant to hydrolysis, photolysis, biodegradation and metabolism, thus they have properties of environmental persistence and bioaccumulative potential. So far, PFCs have been detected in all environmental and biological matrices, including air, surface and ground water, sediments, arctic ice, soils, birds, polar bears, marine organisms, and even in nonoccupationally exposed individuals (Houde et al. 2011). Some PFCs are reported to have adverse effects on plants, animals and humans (Qu et al. 2010; Austin et al. 2003; Stevenson et al. 2006). For example, Qu et al. (2010) reported that $10 \mathrm{mgL}^{-1}$ PFOS treatment could inhibit the elongation and biomass of wheat seedling roots and leaves, and slow the chlorophyll accumulation and soluble protein synthesis. Due to their global distribution, environmental persistence, longdistance transportation, and potential accumulation and toxicity, PFCs have been at the center of an increasing number of environmental monitoring studies. One of the prevalent PFCs, PFOS, as well as its salts and perfluorooctane sulfonyl fluoride, has been added to the persistent organic pollutants (POPs) list of the Stockholm Convention, and was banned in the European Union in 2007 for most applications (Pistocchi and Loos 2009).

Industrial and municipal wastewater treatment plants (WWTPs) have been identified as significant sources for the dispersion of PFCs into the environment. High concentrations of PFCs have been found in the effluent and sludge from WWTPs (Hu et al. 2011; Sun et al. 2011; Bossi et al. 2008; Higgins et al. 2005). Results obtained by Sun et al. (2011) showed that in sewage sludge the total concentrations of perfluoralkyl carboxylates (PFCAs) ranged from 14 to $50 \mathrm{mg} / \mathrm{kg}$ dry matter, and those for PFOS ranged from 15 to $600 \mathrm{mg} / \mathrm{kg}$ dry matter. Aquatic systems have emerged as the primary sink for PFCs in the environment. Pollution levels of PFCs in water, sediment and aquatic biota were reported extensively (Houde et al. 2011; Hu et al. 2011; Bossi et al. 2008; Becker et al. 2010; Murakami et al. 2008). Compared with the well documented concentrations of PFCs in aquatic system, just a few studies have been carried out on the accumulation of PFCs in terrestrial system. It is reported more recently that land application of solid waste from WWTPs resulted in the accumulation of PFCs in soils (Sepulvado et al. 2011; Yoo et al. 2010; Washington et al. 2010). Sepulvado et al. (2011) found that concentrations of PFOS ranged from 80 to $219 \mathrm{ngg}^{-1}$ in municipal biosolids, and ranged from 2 to $483 \mathrm{ngg}^{-1}$ in biosolids-amended soils. In Decatur, Alabama, PFCs and their precursors were reported to be accumulated in soils as a result of industriallycontaminated biosolid land use (Yoo et al. 2010; Washington et al. 2010).

Plants grown in PFCs-contaminated soils may become contaminated with PFCs due to their absorption. The migration of PFCs from soil to plants and their subsequent consumption by animals or human is a likely pathway for PFCs to enter the food chain (Stahl et al. 2009; Lechner and Knapp 2011; Yoo et al. 2011). Thus it is important to understand how PFCs are transported into the plant root system. Carryover of PFCs from soils to agricultural crops was reported to be dose dependent (Stahl et al. 2009) and varied with the plant species and with the substance (Lechner and Knapp 2011). Accumulation of PFCs by grass decreased with PFC increasing chain length (Yoo et al. 2011). The accumulation inhibited the growth and development of plants (Stahl et al. 2009). Although the above works focused on the carryover of PFCs from soil to plants, the uptake mechanisms of PFCs by plants are still not known.

The aim of this study is to characterize the mechanism of two ubiquitous PFCs, PFOS and PFOA, uptake by maize. Various metabolic inhibitors, anion channel blockers and aquaporin competitors were used to test the transport pathways of PFOS and PFOA uptake. To our knowledge, this is the first report to study the uptake mechanisms of PFCs by plant. This result may help to produce PFC-free crop products by means of genetic engineering, to remove PFCs from PFC-contaminated soils or water through phytoremediation, and to model potential uptake for risk assessment.

\section{Materials and methods}

\section{Chemicals}

Perfluorooctane-sulfonic potassium (PFOS, $>98 \%$ ) and perfluorooctanoic acid (PFOA, $>98 \%$ ) were purchased from Sigma-Aldrich Chemical Co. (USA) and were used as-received. Their molecular weights are 538 and $414 \mathrm{gmol}^{-1}$, water solubilities at $25{ }^{\circ} \mathrm{C}$ are 0.57 and $3.4 \mathrm{gL}^{-1}$ (Yamashita et al. 2011) for PFOS and PFOA, respectively. HPLC-grade methyl tert-butyl ether 
(MTBE) was purchased from E.M. Science (Gibbstown, $\mathrm{NJ})$ and tetrabutylammonium sulfate (TBASH) was purchased from Aladdin Chemistry (ShangHai, China). All chemicals are of analytical reagent grade or better.

Plant cultivation

Maize (Zea mays L. cv. TY2) seeds were obtained from the Chinese Academy of Agricultural Sciences (Beijing, China). Seeds were first surface sterilized in $3 \%(w / w)$ $\mathrm{H}_{2} \mathrm{O}_{2}$ for $15 \mathrm{~min}$, thoroughly rinsed with deionized water, soaked in a $6 \mathrm{mmolL}^{-1}$ solution of $\mathrm{Ca}\left(\mathrm{NO}_{3}\right)_{2}$ for $12 \mathrm{~h}$, and subsequently germinated on moist filter paper for 5 days at $25^{\circ} \mathrm{C}$ in the dark. Then the seedlings were transferred to a beaker containing a nutrient solution of major nutrients (one-third-strength of $1 \mathrm{mmolL}^{-1}$ $\mathrm{Ca}\left(\mathrm{NO}_{3}\right)_{2}, 0.5 \mathrm{mmolL}^{-1} \mathrm{Ca}\left(\mathrm{H}_{2} \mathrm{PO}_{4}\right)_{2}, 0.5 \mathrm{mmolL}^{-1}$ $\mathrm{K}_{2} \mathrm{SO}_{4}, 1 \mathrm{mmolL}^{-1} \mathrm{MgSO}_{4}$ and $1.5 \mathrm{mmolL}^{-1}$ $\mathrm{NH}_{4} \mathrm{NO}_{3}$ ) and micronutrients (full-strength of $75 \mu \mathrm{M}$ EDTA-Fe, $46 \mu \mathrm{M} \mathrm{H}_{3} \mathrm{BO}_{3}, 9 \mu \mathrm{molL}^{-1} \mathrm{MnSO}_{4}$, $0.8 \mu \mathrm{molL}^{-1} \mathrm{ZnSO}_{4}, 0.3 \mu \mathrm{molL}^{-1} \mathrm{CuSO}_{4}$ and $0.8 \mu \mathrm{molL}^{-1} \mathrm{Na}_{2} \mathrm{MoO}_{4}$ ). The initial $\mathrm{pH}$ of the nutrient solution was adjusted to 6.0 and the solution was renewed every day. During exposure, plants were grown under controlled conditions (photoperiod $16 \mathrm{~h}$ light $/ 8 \mathrm{~h}$ dark; temperature $25 / 20^{\circ} \mathrm{C}$ at day/night; relative humidity $70 \%$; continuous aeration), unless otherwise stated. Polypropylene beakers were used in all exposure experiments in order to avoid the adsorption of PFCs on the beaker wall. In all studies, 12-day-old uniform maize seedlings were used. After exposure, the plant material from each tub was separated according to its respective plant compartment. The roots and shoots were thoroughly rinsed with distilled water and freeze-dried for $48 \mathrm{~h}$ in a lyophilizer (FD-1, Beijing Boyikang Instrument Ltd.), and then weighed. The dried root and shoot samples were then stored separately at $-20{ }^{\circ} \mathrm{C}$ before chemical analysis.

Effect of PFOS and PFOA on the growth of maize seedlings

Uniform maize seedlings were transferred to the nutrient solutions with PFOS or PFOA concentrations of $0,1.0,10,50,100$ and $200 \mathrm{mgL}^{-1}$ (pH6.0). They were allowed to grow for 10 days under controlled conditions (see above). Plants were harvested, rinsed thoroughly with running water and distilled water, and blotted dry with tissue paper. Plants were then separated into shoots and roots, freeze-dried. The dry weights were recorded. Plants grown in nutrient solution without PFOS or PFOA addition were used as control. There were four replicates per treatment.

Time-dependent uptake and transport of PFOS and PFOA by maize

Uniform maize seedlings were transferred to nutrient solution (pH6.0) containing $1.0 \mathrm{mgL}^{-1}$ PFOS or PFOA. At increasing exposure time intervals $(2,5$, 10, 20, 50 and $100 \mathrm{~h}$ ), maize seedlings were sampled and prepared. The concentrations of PFOS and PFOA in maize were determined. All experiments were performed in quadruplicate.

\section{Concentration-dependent uptake of PFOS}

Uniform maize seedlings were transferred to nutrient solution containing various concentrations of PFOS $\left(0,0.1,0.2,0.5,0.7\right.$, and $\left.1.0 \mathrm{mgL}^{-1}\right)$ or PFOA $\left(0,0.1,0.2,0.5,0.7\right.$ and $\left.1.0 \mathrm{mgL}^{-1}\right)$. After $1 \mathrm{~h}$ exposure, the maize seedlings were sampled and prepared. The concentrations of PFOS and PFOA in maize roots were determined. All experiments were performed in quadruplicate.

Effect of metabolic, aquaporin and anion-channel inhibitors on the uptake of PFOS and PFOA

PFOS and PFOA uptake by maize as influenced by metabolic, aquaporin and anion-channel inhibitors was investigated. $0.1 \mathrm{mmolL}^{-1}$ sodium azide $\left(\mathrm{NaN}_{3}\right)$ or $0.6 \mathrm{mmolL}^{-1}$ sodium vanadate $\left(\mathrm{Na}_{3} \mathrm{VO}_{4}\right)$ was applied as metabolic inhibitors according to the methods reported with some modifications (Thompson et al. 2000; Krapfenbauer et al. 2003; Herrmann et al. 2003). $1 \mu \mathrm{molL}^{-1} \mathrm{AgNO}_{3}$ or $1 \mathrm{mmolL}^{-1}$ glycerol was used as aquaporin inhibitors (Kong et al. 2007). $10 \mu \mathrm{molL}^{-1}$ anthracene-9-carboxylic acid (9-AC, Aladdin Chemistry, Co. Ltd, China), or $5 \mu \mathrm{molL}^{-1} 4,4^{\prime}$-diisothiocyanostibene-2,2'-disulfonate (DIDS, Tokyo Chemical Industry, Co. Ltd, Japan), or $5 \mu \mathrm{molL}^{-1} 5$-nitro 2(3-phenylpropylamine) benzoic acid (NPPB, Tokyo Chemical Industry, Co. Ltd, Japan) was used as anion channel inhibitors (You et al. 2010; Matveyeva et al. 2003). Maize seedlings were transferred to $400 \mathrm{~mL} \mathrm{nu}-$ trient solution containing $1.0 \mathrm{mgL}^{-1}$ PFOS or PFOA with metabolic or aquaporin or anion-channel inhibitors. 
Maize seedlings grown in solutions without any inhibitors were used as control. The uptake experiments were performed in a period of $5 \mathrm{~h}$. The maize seedlings were sampled and prepared. The concentrations of PFOS and PFOA in maize roots were determined. All experiments were performed in quadruplicate.

\section{Uptake competition between PFOS and PFOA}

The maize seedlings were treated with $1.0 \mathrm{mgL}^{-1}$ PFOS, $1.0 \mathrm{mgL}^{-1}$ PFOA, and a mixture of $1.0 \mathrm{mgL}^{-1}$ PFOS and $1.0 \mathrm{mgL}^{-1}$ PFOA, respectively. After $5 \mathrm{~h}$ exposure, the maize seedlings were sampled. The concentrations of PFOS and PFOA in maize roots were determined. All experiments were performed in quadruplicate.

\section{Determination of PFOS and PFOA in maize}

PFOS and PFOA were extracted from maize according to the method of Hansen et al. (2001) with some modification. Briefly, $0.5 \mathrm{~g}$ maize roots or shoots, $4 \mathrm{~mL}$ of $0.125 \mathrm{molL}^{-1}$ sodium carbonate buffer, $1 \mathrm{~mL}$ of $0.5 \mathrm{molL}^{-1}$ TBAHS were added to a $15-\mathrm{mL}$ polypropylene tube for extraction. After thorough mixing, $5 \mathrm{~mL}$ of MTBE was added to the solution, and the mixture was shaken for $20 \mathrm{~min}$. The organic and aqueous layers were separated by centrifugation, and MTBE was removed from the solution. The aqueous mixture was rinsed with MTBE and separated twice more. All collected supernatants from both extractions which contained the organic fraction were combined together. The solvent was allowed to evaporate under nitrogen before being reconstituted in $1.0 \mathrm{~mL}$ of methanol. The sample was vortex mixed for $30 \mathrm{~s}$ and passed through a $0.22 \mu \mathrm{m}$ nylon mesh filter before determination. Extraction recoveries were determined by spiking the standards of PFOA and PFOS with different concentrations into the plant samples, and the recoveries were $92-105 \%$, showing the validity of the extraction.

Plant extracts were analyzed on a Waters Quattro Premier XE tandem mass spectrometer interfaced with a Waters Acquity ultra performance liquid chromatograph (UPLC/MS/MS). All system operations were controlled by Waters MassLynx 4.1 and QuanLynx 4.1. Ten microliters of extract were introduced to a Waters XTerra C18 analytical column, $100 \times 2.1 \times 2.1$ $(\mathrm{mm}$ length $\times \mathrm{mm}$ inside diameter $\times \mu \mathrm{m}$ particle size $)$, maintained at $40^{\circ} \mathrm{C}$. The UPLC was operated using a mobile phase consisting of $10 \mathrm{mmolL}^{-1}$ ammonium acetate/acetonitrile $(50: 50, v / v)$, which was maintained at a flow rate of $0.2 \mathrm{mlmin}^{-1} \cdot{ }^{13} \mathrm{C}_{4}$ PFOA served as internal standards.

Upon elution from the UPLC, extracts were introduced to the mass spectrometer operated in ESI(-) mode with the capillary potential set at $-3400 \mathrm{~V}$, the extractor potential at $-2 \mathrm{~V}$ and the radio frequency (RF) lens potential at $0.3 \mathrm{~V}$. The source temperature was maintained at $120{ }^{\circ} \mathrm{C}$. The desolvation gas from the $\mathrm{N}_{2}$ generator was maintained at $350{ }^{\circ} \mathrm{C}$ and a flow rate of $600 \mathrm{Lh}^{-1}$. The cone gas, also supplied by the $\mathrm{N}_{2}$ generator, was set to a flow rate of $50 \mathrm{Lh}^{-1}$. The low- and high-mass resolutions in the first quadrupole both were set to 13.0 (unitless ratio of direct to $R F$ current voltages) and the ion energy was set to $0.5 \mathrm{eV}$. In the collision cell, the entrance and the exit were set to $-1 \mathrm{~V}$. The Ar collision gas was set to flow at $0.10 \mathrm{mLmin}^{-1}$. The collision energies, cone voltages and MS/MS parameters for the instrument were optimized for individual analytes (Table 1).

\section{Modeling}

To model PFOS and PFOA accumulation and calculate their uptake and transport rates, the experimental data were fitted with one-compartment first-order kinetics (Wen et al. 2011):

$\mathrm{Q}_{\mathrm{t}}=\mathrm{Q}_{0}+\alpha / \mathrm{k}_{\mathrm{e}}\left(1-\mathrm{e}^{-\mathrm{ket}}\right)$

where $Q_{t}$ is the total concentration of PFOS and/or PFOA $\left(\mathrm{mg} \mathrm{kg}^{-1}\right)$ in maize at time $\mathrm{t}(\mathrm{h}), \mathrm{k}_{\mathrm{e}}$ is the excretion rate constant $\left(\mathrm{h}^{-1}\right)$, and $\alpha$ is the uptake flux constant $\left(m g \mathrm{~kg}^{-1} \mathrm{~h}^{-1}\right.$ ), which equals $\mathrm{k}_{\mathrm{u}} \mathrm{C}_{0}$, where $\mathrm{k}_{\mathrm{u}}$ is the uptake rate constant $\left(\mathrm{L} \mathrm{kg}^{-1} \mathrm{~h}^{-1}\right)$ and $\mathrm{C}_{0}$ is the bioavailable external concentration in solution $\left(\mathrm{mg} \mathrm{L}^{-1}\right)$. The concentration of PFOS and PFOA in roots and shoots at

Table 1 Optimized parameters for the determination of target PFOS and PFOA

\begin{tabular}{lllll}
\hline Analytes & $\begin{array}{l}\text { Transition } \\
\text { monitored } \\
(\mathrm{m} / \mathrm{z})\end{array}$ & $\begin{array}{l}\text { Collision } \\
\text { energy } \\
(\mathrm{eV})\end{array}$ & $\begin{array}{l}\text { Cone } \\
\text { voltage } \\
(\mathrm{V})\end{array}$ & $\begin{array}{l}\text { Elution } \\
\text { time } \\
(\mathrm{min})\end{array}$ \\
\hline PFOS & $498.54 \rightarrow 79.88$ & 42 & 62 & 7.50 \\
PFOA & $412.61 \rightarrow 168.76$ & 18 & 14 & 3.42 \\
${ }^{13} \mathrm{C}-\mathrm{PFOA}$ & $416.59 \rightarrow 168.76$ & 18 & 14 & 3.42 \\
\hline
\end{tabular}


the beginning of the experiment, $\mathrm{Q}_{0}$ was assumed to be a pool of constant magnitude. Subsequently, Eq. 1 was used to calculate steady-state tissue PFOS or PFOA concentrations $\left(\mathrm{C}_{\mathrm{ss}}\right)$ for maize roots and shoots, which equals the ratio of the uptake and transport flux constant to the elimination constant $\left(\alpha / \mathrm{k}_{\mathrm{e}}\right)$. The steady-state concentrations were used to calculate bioaccumulation factors (the ratio of PFOS or PFOA concentration in maize root to the solution concentration, $\mathrm{BAF}$ ) and transport factor (the ratio of the PFOS or PFOA concentration in maize shoot to those in maize root, TF).

Data from the relatively short uptake period $(1 \mathrm{~h})$ were used to investigate the uptake while minimizing the possible efflux of PFOS and PFOA across the plasma membrane back into the external solution. The uptake kinetics of PFOS and PFOA was described with a Michaelis-Menten equation (Zhan et al. 2010):

$\mathrm{V}=\mathrm{V}_{\max } \mathrm{C} /\left(\mathrm{K}_{\mathrm{m}}+\mathrm{C}\right)$

where $\mathrm{V}$ is the uptake rate $\left(\mathrm{mg} \mathrm{kg}^{-1} \mathrm{~h}^{-1}\right), \mathrm{C}$ is the total PFOS or PFOA concentration in the solution $(\mathrm{mg}$ $\left.\mathrm{L}^{-1}\right)$, and $\mathrm{V}_{\max }\left(\mathrm{mg} \mathrm{kg}^{-1} \mathrm{~h}^{-1}\right)$ and $\mathrm{K}_{\mathrm{m}}\left(\mathrm{mg} \mathrm{L}^{-1}\right)$ are the maximum uptake rate and Michaelis-Menten rate constant, respectively.

\section{Statistical analyses}

All statistical analyses were conducted with the software SPSS 11.5 for Windows (SPSS Inc., Chicago, IL). One-way ANOVA was used to assess the significance of the difference between groups, and nonlinear regression analyses were conducted by the leastsquares method. Statements of significant differences are based on $P<0.05$.

\section{Results}

Toxicity of PFOS and PFOA

Effects of PFOS or PFOA on the biomass of maize shoots and roots are presented in Fig. 1. PFOS or PFOA treatment at the level of $1 \mathrm{mg} / \mathrm{L}$ exhibited no toxic effects on maize growth. When the concentration of PFOS or PFOA was $10 \mathrm{mgL}^{-1}$, the maize root and shoot fresh weights decreased significantly $(P<0.05)$. Increases in the concentration of PFOS or PFOA in the growth medium led to a more pronounced reduction in root and shoot dry weight. When the concentrations of PFOS or PFOA were higher than $200 \mathrm{mgL}^{-1}$, PFOS decreased maize biomass of $68 \%$ (root) and $45 \%$ (shoot), while PFOA decreased biomass of $87 \%$ (root) and $58 \%$ (shoot), indicating that PFOA was more toxic than PFOS at higher concentrations (Fig. 1a and b). When PFOS and PFOA concentrations were $200 \mathrm{mgL}^{-1}$, the ratios of shoot dry weight/root dry weight were 1.7 and 3.2 times those of control for PFOS and PFOA, respectively.

Time-dependent kinetics of PFOS and PFOA uptake and transport

The time course for PFOS and PFOA (Fig. 2) uptake and transport into maize roots and shoots could be separated into two periods: a fast and a slow process. The individual uptake and transport data of PFOS and PFOA fitted Eq. 1 well, with high $R^{2}$ values $(>0.97)$ and low mean weighted square error (Fig. 2, Table 2). The uptake rate content $\left(\mathrm{k}_{\mathrm{u}}\right)$ of PFOS was 2.58 times that of PFOA, while the elimination rate content $\left(\mathrm{k}_{\mathrm{e}}\right)$ of PFOA was 1.22 times that of PFOS. The higher $\mathrm{k}_{\mathrm{u}}$ and lower $\mathrm{k}_{\mathrm{e}}$ of PFOS resulted in the higher $\mathrm{C}_{\mathrm{ss}}$ and BAF values of PFOS when compared with those of PFOA. The calculated $\mathrm{C}_{\mathrm{ss}}$ of PFOS and PFOA in maize roots were within the range of their concentrations at the hour $100\left(\mathrm{C}_{100}\right)$, which indicated that the uptake of PFOS or PFOA reached saturation during uptake period.

PFOA concentration in maize shoots increased with the exposure time and approached a plateau (Fig. 2). The concentration of PFOS in maize shoots increased slowly towards a plateau. The calculated $\mathrm{C}_{\mathrm{ss}}$ of PFOS in maize shoots was 1.5 times that of $\mathrm{C}_{100}$, indicating that the transport of PFOS did not reach saturation on hour 100. The PFOS transport factor calculated by the ratio of root $\mathrm{C}_{\mathrm{ss}}$ to shoot $\mathrm{C}_{\mathrm{ss}}$ was 1.6 times that of PFOA.

Concentration-dependent uptake of PFOS and PFOA

Concentration-dependent of PFOS or PFOA uptake by maize roots were nonlinear, and could be adequately described by the Michaelis-Menten function (Fig. 3, $R^{2}>0.990$ ), with the apparent $\mathrm{V}_{\max }$ of $38.3 \pm 2.8 \mathrm{mgkg}^{-1} \mathrm{~h}^{-1}$ and $\mathrm{K}_{\mathrm{m}}$ of $1.92 \pm 0.19 \mathrm{mgL}^{-1}$ for PFOS, and $\mathrm{V}_{\max }$ of $2.79 \pm 0.10 \mathrm{mgkg}^{-1} \mathrm{~h}^{-1}$ and $\mathrm{K}_{\mathrm{m}}$ of $0.184 \pm 0.022 \mathrm{mgL}^{-1}$ for PFOA. 


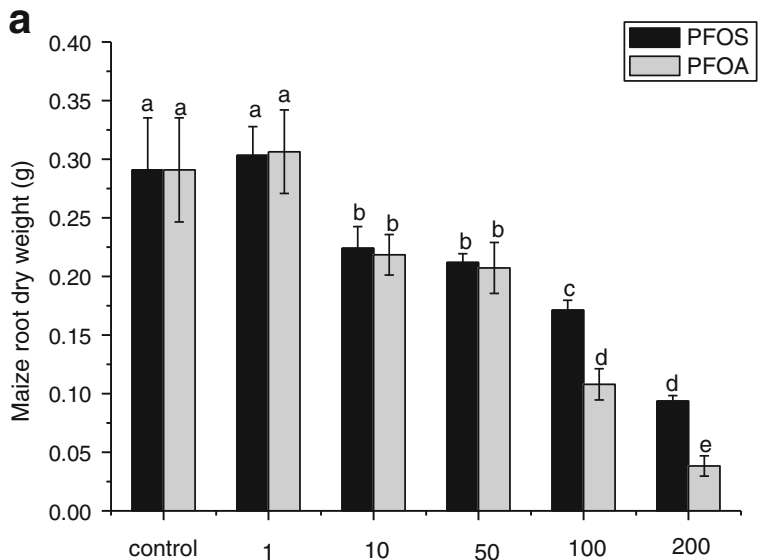

PFOS or PFOA concentrations in solutions $\left(\mathrm{mg} \mathrm{L}^{-1}\right)$

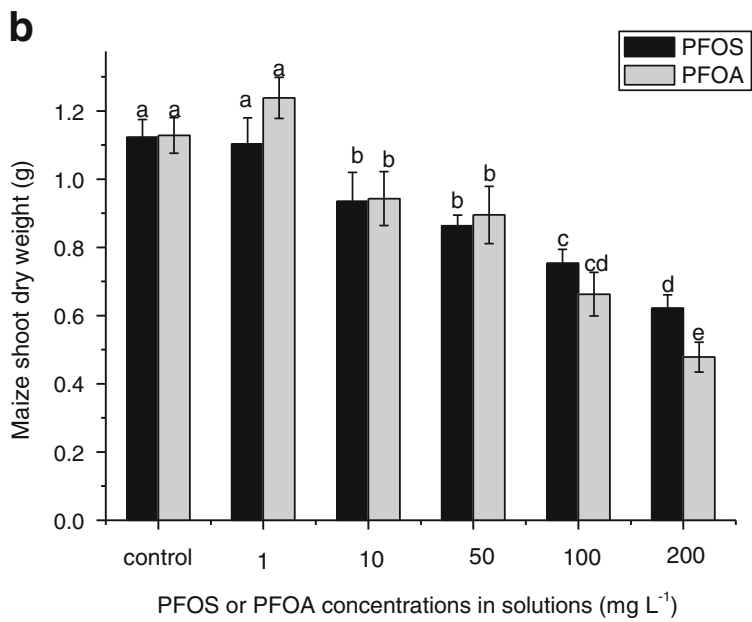

Fig. 1 Effects of PFOS or PFOA on maize root (a) and shoot (b) dry weights. Each point is the average of four replicates, and bars represent $\pm \mathrm{SE}$ of the mean. Different letters indicate significant differences at $p<0.05$

Effect of metabolic, aquaporin and anion channel inhibitors on PFOS and PFOA uptake by maize

Uptake of PFOS was insensitive to metabolic inhibitors $\left(\mathrm{NaN}_{3}\right.$ and $\left.\mathrm{Na}_{3} \mathrm{VO}_{4}\right)$. In contrast, uptake of PFOA was reduced by 83 and $43 \%$ when treated with $\mathrm{NaN}_{3}$ and $\mathrm{Na}_{3} \mathrm{VO}_{4}$, respectively (Fig. 4a). PFOS uptake was decreased by 31 and $25 \%$ when plants were treated with aquaporin inhibitors, $\mathrm{AgNO}_{3}$ and glycerol, respectively, while aquaporin inhibitors had no effect on PFOA uptake (Fig. 4b). Anion channel blockers, 4, 4'-diisothiocyanostibene-2, 2'-disolfonate (DID) and 5-nitro 2-(3-phenylpropylamine) benzoic acid (NPPB) inhibited the uptake of PFOS by 33 and $30 \%$, respectively. Anion channel blocker anthracene-

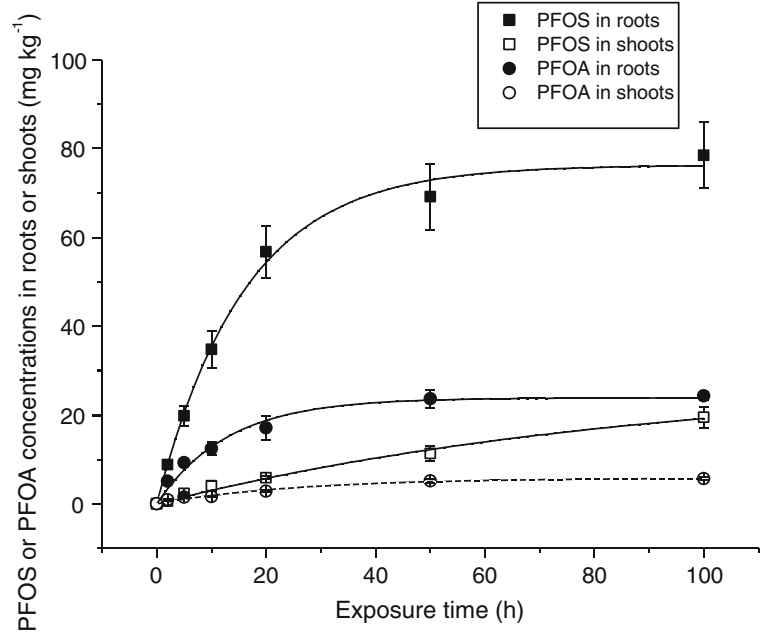

Fig. 2 Uptake and transport kinetics of PFOS and PFOA in maize following a $100 \mathrm{~h}$ exposure to $10 \mathrm{mgL}^{-1}$ PFOS or PFOA. Lines represent the fits to Eq. 1 for PFOS or PFOA in roots and shoots, respectively

9-carboxylic acid (9-AC) decreased the uptake of PFOA by $28 \%(P<0.05$, Fig. $4 \mathrm{c})$.

Competitive absorption of PFOS and PFOA

The presence of PFOA did not affect PFOS uptake by maize roots. In turn, no significant difference of PFOA uptake was found with and without PFOS (Fig. 5). Therefore, no competitive inhibition occurs when PFOS and PFOA are present in culture solution.

\section{Discussion}

Toxicity of PFOS and PFOA

PFOS or PFOA significantly inhibited the maize growth at concentrations higher than $10 \mathrm{mgL}^{-1}$. Root growth was more sensitive to PFOS or PFOA than that of shoot. Plant roots were the first point of contact for toxic PFOS or PFOA in the growth media. When the growth of roots was inhibited, the uptake of nutrition might be restrained, resulting in the decreases of the plant biomass finally (Lindo et al. 2000). Similar results of plant root growth inhibited by PFOS or PFOA treatments were reported based on hydroponic (Liu 2009; Ding et al. 2012; Qu et al. 2010) and soil (Zhao et al. 2011) studies. Liu (2009) reported that PFOS was more toxic than PFOA for cucumber, 
Table 2 Estimates of kinetic parameters for PFOS and PFOA uptake and transport

\begin{tabular}{lll}
\hline & PFOS & PFOA \\
\hline Roots & & \\
$\alpha\left(\mathrm{mg} \mathrm{kg}^{-1} \mathrm{~h}^{-1}\right)$ & $4.758 \pm 0.274$ & $1.843 \pm 0.193$ \\
$\mathrm{k}_{\mathrm{u}}\left(\mathrm{L} \mathrm{kg}^{-1} \mathrm{~h}^{-1}\right)$ & 4.758 & 1.843 \\
$\mathrm{k}_{\mathrm{e}}\left(\mathrm{h}^{-1}\right)$ & $0.063 \pm 0.004$ & $0.077 \pm 0.006$ \\
$\mathrm{C}_{\mathrm{ss}}\left(\mathrm{mg} \mathrm{kg}^{-1}\right)$ & 75.52 & 23.94 \\
$\mathrm{C}_{100}\left(\mathrm{mg} \mathrm{kg}^{-1}\right)^{\mathrm{a}}$ & $78.48 \pm 7.48$ & $24.30 \pm 0.81$ \\
$\mathrm{BAF}^{\mathrm{b}}$ & 75.52 & 23.94 \\
$R^{2}$ & 0.991 & 0.982 \\
$\mathrm{MWSE}^{\mathrm{c}}$ & 0.0018 & 0.0383 \\
$\mathrm{Shoots}$ & & \\
$\alpha\left(\mathrm{mg} \mathrm{kg}^{-1} \mathrm{~h}^{-1}\right)$ & $0.319 \pm 0.031$ & $0.225 \pm 0.029$ \\
$\mathrm{k}_{\mathrm{e}}\left(\mathrm{h}^{-1}\right)$ & $0.011 \pm 0.003$ & $0.039 \pm 0.007$ \\
$\mathrm{C}_{\mathrm{ss}}\left(\mathrm{mg} \mathrm{kg}^{-1}\right)$ & 29.00 & 5.76 \\
$\mathrm{C}_{100}\left(\mathrm{mg} \mathrm{kg}^{-1}\right){ }^{\mathrm{a}}$ & $19.48 \pm 2.39$ & $5.67 \pm 0.34$ \\
$\mathrm{TF}^{\mathrm{d}}$ & 0.384 & 0.241 \\
$R^{2}$ & 0.991 & 0.976 \\
$\mathrm{MWSE}^{\mathrm{c}}$ & 0.0456 & 0.0691 \\
\hline
\end{tabular}

${ }^{\mathrm{a}}$ Concentrations of PFOS or PFOA in maize roots or shoots at hour 100

${ }^{\mathrm{b}}$ Bioaccumulation factor, which is calculated by the ratio of root $\mathrm{C}_{\mathrm{ss}}$ to the pore water PFCs concentration

${ }^{\mathrm{c}}$ Mean weighted square error, equal to $1 / v \sum\left[\left(\mathrm{q}_{\text {measured }}-\mathrm{q}_{\text {model }}\right)^{2}\right.$ $/ q_{\text {measured }}^{2}$., where $v$ is the amount of freedom, $v=\mathrm{N}-2$

${ }^{\mathrm{d}}$ Transport factor, which is calculated by the ratio of $\operatorname{root} \mathrm{C}_{\mathrm{ss}}$ to shoot $\mathrm{C}_{\mathrm{ss}}$

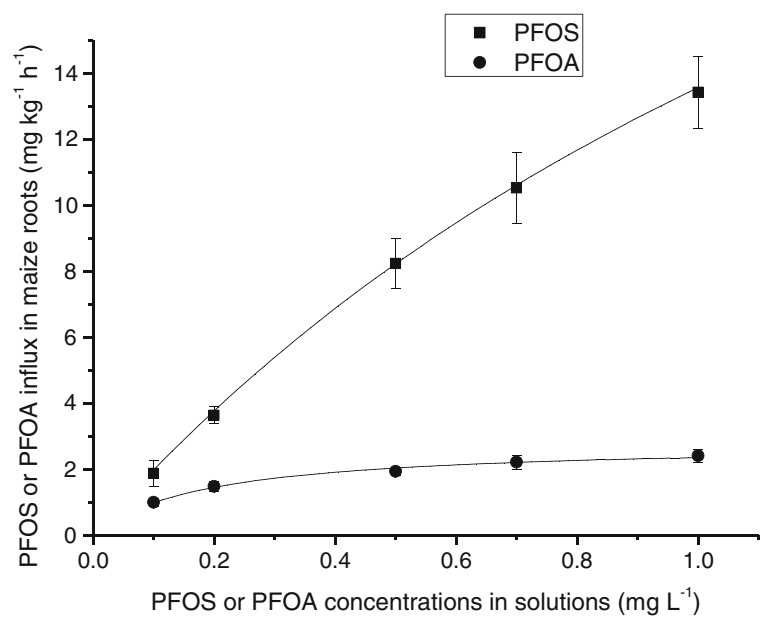

Fig. 3 Concentration-dependent uptake of PFOS and PFOA by maize roots. Lines represent the fits to Eq. 2 . The uptake time is $1 \mathrm{~h}$
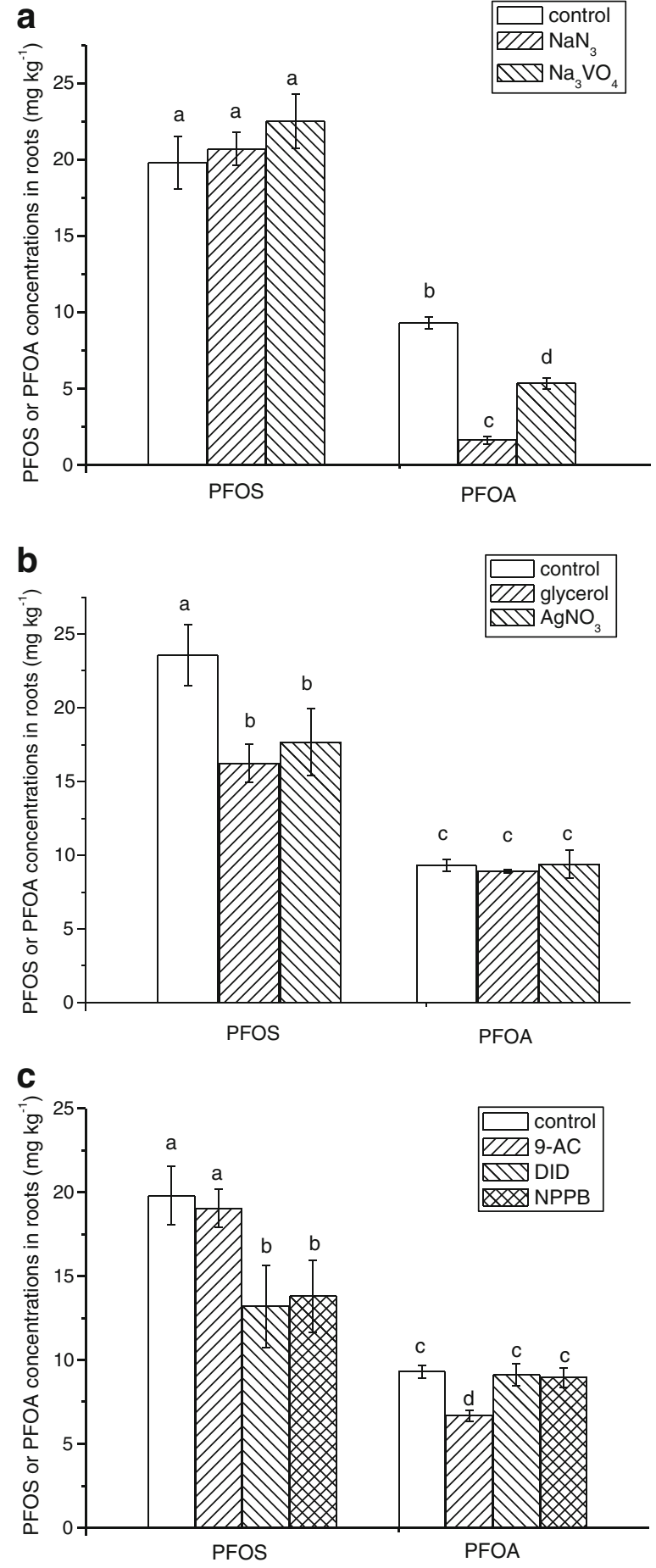

Fig. 4 Effect of metabolic inhibitors (a), aquaporin (b) and anion channel (c) inhibitors on PFOS and PFOA uptake by maize. Different letters indicate significant differences at $p<0.05$

lettuce and pakchoi. However, results obtained in this study showed that PFOA was more toxic than PFOS at 


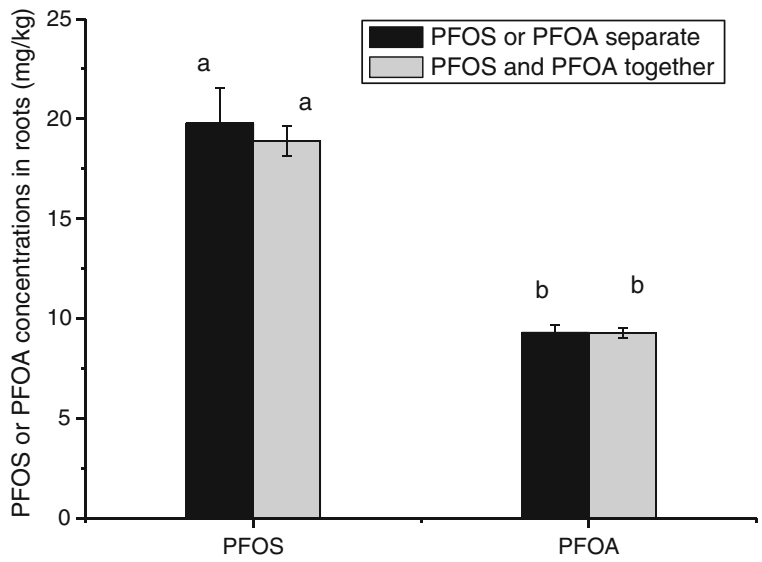

Fig. 5 Uptake competitions between PFOS and PFOA. Different letters indicate significant differences at $p<0.05$

higher concentrations. Stahl et al. (2009) suggested that toxic effect of PFOS and PFOA to plants was dependent on plant species.

\section{Uptake mechanisms of PFOS and PFOA}

Shi et al. (2012) investigated the distribution of PFCs in Baiyangdian Lake, China. They found that PFOA was the dominant PFCs in floating plants, while PFOS was the dominant PFCs in fish. Results obtained by Lechner and Knapp (2011) showed that PFOA concentrations in carrots and potatoes were higher than those of PFOS. However, PFOS concentrations in maize ears were higher than PFOA (Stahl et al. 2009). Our finding showed that the steady concentrations of PFOS in maize roots and shoots were higher than those of PFOA (Fig. 2 and Table 2).

Organic compounds could be taken up via passive process, which involves simple and facilitated diffusion, and/or active process, depending on the properties and the concentrations of the organic compounds and the biological species (Zhan et al. 2010). The absorption of non-ionized organic compounds by roots of higher plants is generally regarded as a passive, diffusive, partitioning and nonmetabolic process (Li et al. 2010; Chiou et al. 2001). Compared with the uptake of non-ionized organic compounds, mechanisms for organic ion absorption still remain poorly understood (Trapp et al. 2010). Uptake of organic anion atrazine and phenol appears to proceed essentially by simple passive mechanism, as evaluated by a partition-limited model ( $\mathrm{Su}$ and $\mathrm{Zhu}$ 2006) whereas uptake of glyphosate by broad bean is an active process and needs transporters (Denis and Delrot 1993). Michaelis-Menten is a useful model to examine transporter-mediated uptake processes. When uptake kinetics followed a Michaelis-Menten pattern, it could indicate uptake via a carrier-mediated process, by analogy to the relationship between an enzyme and its substrate (Zhan et al. 2010). Yang et al. (2010) revealed that uptake of perfluorooctanoate (PFO) by OAT4-expressing CHO cells is a carrier-mediated process, which was demonstrated by a kinetics that can be described by Michaelis-Menten equation. In this study, absorption of PFOS and PFOA were nonlinear, and fitted Michaelis-Menten model well (Fig. 3), indicating that the uptake of PFOS or PFOA by maize roots was likely a carrier-mediated processes.

Carrier-mediated process includes active or facilitated passive absorption (Wang et al. 2011). To further distinguish active transport from facilitated diffusion, metabolic inhibitors were employed to affect active uptake by disabling cellular energy production. 2,4dinitrophenol $(2,4-\mathrm{DNP})$ is considered primarily as metabolic inhibitor (Kong et al. 2007; Zhan et al. 2010; Wang et al. 2011). It is regarded as an uncoupler of oxidative phosphorylation, and of proton-coupled fluxes at the plasma membrane and endomembrane via the dissipation of trans-membrane electrochemical gradients of protons (Kong et al. 2007). However, in this study, obvious wilting was found after $3 \mathrm{~h} \mathrm{2,4-}$ DNP treatment. Thus, two other often applied metabolic inhibitors, $\mathrm{NaN}_{3}$ and $\mathrm{Na}_{3} \mathrm{VO}_{4}$ were used. $\mathrm{NaN}_{3}$ is an oxidative phosphorylation inhibitor (Thompson et al. 2000), and $\mathrm{Na}_{3} \mathrm{VO}_{4}$ is a phosphatase inhibitor (Krapfenbauer et al. 2003). Uptake of PFOS was insensitive to $\mathrm{NaN}_{3}$ or $\mathrm{Na}_{3} \mathrm{VO}_{4}$, whereas uptake of PFOA was inhibited by $\mathrm{NaN}_{3}$ and $\mathrm{Na}_{3} \mathrm{VO}_{4}$ at the rate of $83 \%$ and $43 \%$, respectively (Fig. $4 a$ ). These data indicated that transport of PFOA into maize roots was likely an energy-dependent process, while transport of PFOS might be a carrier-mediated diffusion process.

To investigate whether PFOS or PFOA uptake by plant could be facilitated by water channels, $\mathrm{AgNO}_{3}$ and glycerol were used to inhibit or compete for the aquaporins in maize roots. Both glycerol and silver are widely used to assay aquaporin activity (Kong et al. 2007), but their inhibitory mechanisms differ greatly. Silver may react with the sulfhydryl group of a cysteine in the vicinity of the conserved NPA motif, thus effectively blocks the constriction region of the water channel. Glycerol is a substrate for aquaporins. It 
inhibits aquaporins by substrate competition (Meharg and Jardine 2003). Results obtained by Su et al. (2005) indicated that organic anion atrazine is taken up via water channel. Our finding that neither glycerol nor $\mathrm{AgNO}_{3}$ inhibited PFOA uptake by maize roots significantly (Fig. 4b) suggested that aquaporins may not be a major channel for PFOA transport into maize root. On the contrary, PFOS uptake decreased by $31 \%$ and $25 \%$ of control when exposed to $1 \mu \mathrm{molL}^{-1} \mathrm{AgNO}_{3}$ and $1 \mathrm{mmolL}^{-1}$ glycerol, respectively, indicating that aquaporins may be at least partly involved in PFOS absorption.

In order to further study the mechanism of PFOS and PFOA uptake by maize, effect of various kind of anion channel blockers, 9-AC, DID, NPPB on the uptake of PFOS and PFOA were investigated. 9-AC and NPPB were reported to block uptake through slow anion channels, while DID through rapid anion channels (Barbier-Brygoo et al. 2000; Schroeder et al. 1993). The finding that absorption of PFOS was insensitive to 9-AC, but inhibited by DID and NPPB, and the absorption of PFOA was only reduced by 9 AC (Fig. 4c) indicated that the influx of PFOS and PFOA into maize roots was mediated by anion channels, and the absorption of PFOS and PFOA may follow different pathways. PFOS and PFOA are PFCs, which have similar perfluoroalkyl tail of varying chain length and different polar head group (sulfonate for PFOS and carboxylate for PFOA). The noncompetitive effect of PFOS and PFOA upon maize root uptake further suggested that uptake of PFOS and PFOA did not share a common transport mechanism though both of the uptake proceeded with a carrier-mediated system.

\section{Conclusions}

PFOS and PFOA are potentially phytotoxic to and are accumulated by higher plants. Results from the present study demonstrate that maize absorption of PFOS and PFOA may follow different pathways. Uptake of PFOA by maize root is energy dependent active process, and anion channel may be involved in the uptake. Uptake of PFOS is carrier-mediated passive process, which may via aquaporins and anion channel in root cell membranes. The accumulation of PFOS and PFOA in plants may pose health risks to animals and humans. Therefore, further research should focus on the translocation, and accumulation mechanisms of PFOS and PFOA, especially by crops and vegetables.

Acknowledgments This study was supported by the National Natural Science Foundation of China (Grant No. 40730740).

\section{References}

Austin ME, Kasturi BS, Barber M, Kannan K, MohanKumar PS, MohanKumar SMJ (2003) Neuroendocrine effects of perfluorooctane sulfonate in rats. Environ Health Perspect 111:1485-1489

Barbier-Brygoo H, Vinauger M, Colcombet J, Ephritikhine G, Frachisse J, Maurel C (2000) Anion channels in higher plants: functional characterization, molecular structure and physiological role. Biochim Biophys Acta 1465:199-218

Becker AM, Suchan M, Gerstmann S, Frank H (2010) Perfluorooctanoic acid and perfluorooctane sulfonate released from a waste water treatment plant in Bavaria, German. Environ Sci Pollut Res 17:1502-1507

Bossi R, Strand J, Sortkjær O, Larsen MM (2008) Perfluoroalkyl compounds in Danish wastewater treatment plants and aquatic environments. Environ Int 34:443-450

Chiou CT, Sheng G, Manes M (2001) A partition-limited model for the plant uptake of organic contaminants from soil and water. Environ Sci Technol 35:1437-1444

Denis M, Delrot S (1993) Carrier-mediated uptake of glyphosate in broad bean (Vicia faba) via a phosphate transporter. Physiol Plant 87:569-575

Ding G, Wouterse M, Baerselman R, Peijnenburg WJGM (2012) Toxicity of polyfluorinated and perfluorinated compounds to lettuce (Lachuca sativa) and green algae (Pseudokirchneriella subcapitata). Arch Environ Contam Toxicol 62:49-55

Hansen KJ, Clemen LA, Ellefson ME, Johnson HO (2001) Compound-specific, quantitative characterization of organic fluorochemicals in biological matrices. Environ Sci Technol 35:766-770

Herrmann L, Dittmar T, Erdmann KS (2003) The protein tyrosine phosphatase PTP-BL associates with the midbody and is involved in the regulation of cytokinetsis. Mol Biol Cell 14:230-240

Higgins CP, Field JA, Criddle CS, Luthy RG (2005) Quantitative determination of perfluorochemical in sediments and domestic sludge. Environ Sci Technol 39:3946-3956

Houde M, Martin JW, Letcher RJ, Solomon KR, Muir DCG (2006) Biological monitoring of polyfluoroalkyl substances: a review. Environ Sci Technol 40:3463-3473

Houde M, De Silva AO, Muir DCG, Letcher RJ (2011) Monitoring of perfluorinated compounds in aquatic biota: an updated review. Environ Sci Technol 45:7962-7973

Hu JY, Yu J, Tanaka S, Fujii S (2011) Perfluorooctane sulfonate (PFOS) and perfluorooctanoic acid (PFOA) in water environment of Singapore. Water Air Soil Pollut 216:179-191

Kong WD, Zhu YG, Liang YC, Zhang J, Smith FA, Yang M (2007) Uptake of oxytetracycline and its phytotoxicity to alfalfa (Medicago sativa L.). Environ Pollut 147:187-193 
Krapfenbauer K, Fountoulakis M, Lubec G (2003) A rat brain protein expression map including cytosolic and enriched mitochondrial and microsomal fractions. Electrophoresis 24:1847-1870

Lechner M, Knapp H (2011) Carryover of perfluorooctanoic acid (PFOA) and perfluorooctane sulfonate (PFOS) from soil to plant and distribution to the different plant compartments studied in cultures of carrots (Daucus carota ssp. sativus), potatoes (Solanum tuberosum), and cucumbers (Cucumis Sativus). J Agric Food Chem 59:11011-11018

Li XY, Zhu YH, Wu T, Zhang SZ, Christie P (2010) Using a novel petroselinic acid embedded cellulose acetate membrane to mimic plant partitioning and in vivo uptake of polycyclic aromatic hydrocarbons. Environ Sci Technol 44:297-301

Lindo FC, Azinheira HG, Barreiro MG (2000) Aluminum toxicity in maize: Biomass production and nutrient uptake and translocation. J Plant Nutr 23:151-160

Liu MH (2009) Toxicity of perfluorooctane sulfonate and perfluorooctanoic acid to plants and aquatic invertebrates. Environ Toxicol 24:95-101

Matveyeva NP, Andreyuk DS, Yermakov IP (2003) Transport of $\mathrm{Cl}^{-}$across the plasma membrane during pollen grain germination in tobacco. Biochem Mosc 68:1247-1251

Meharg AA, Jardine L (2003) Arsenite transport into paddy rice (Oryza sativa) roots. New Phytol 157:39-44

Murakami M, Imamura E, Shinohara H, Kiri K, Muramatsu Y, Harada A, Takada H (2008) Occurrence and sources of perfluorinated surfactants in rivers in Japan. Environ Sci Technol 42:6566-6572

Pistocchi A, Loos R (2009) A map of European emissions and concentrations of PFOS and PFOA. Environ Sci Technol 43:9237-9244

Qu B, Zhao H, Zhou J (2010) Toxic effects of perfluorooctane sulfonate (PFOS) on wheat (Triticum aestivum L.) plant. Chemosphere 79:555-560

Schroeder JI, Schmidt C, Sheaffer J (1993) Identification of high-affinity slow anion channel blockers and evidence for stomatal regulation by slow anion channels in guard cells. The Plant Cell 5:1831-1841

Sepulvado JG, Blaine AC, Hundal LS, Higgins CP (2011) Occurrence and fate of perfluorochemicals in soil following the land application of municipal biosolids. Environ Sci Technol 45:8106-8112

Shi YL, Pan YY, Wang JM, Cai YQ (2012) Distribution of perfluorinated compounds in water, sediment, biota and floating plants in Baiyangdian Lake, China. J Environ Monit 14:636-642

Stahl T, Heyn J, Thiele H, Hüther J, Failing K, Georgii S, Brunn H (2009) Carryover of perfluorooctanoic acid (PFOA) and perfluorooctane sulfonate (PFOS) from soil to plant. Arch Environ Contamin Toxicol 57:289-298

Stevenson CN, MacManus-Spencer LA, Luckenbach T, Luthy RG, Epel D (2006) New perspectives on perfluorochemical ecotoxicology: inhibition and induction of an efflux transporter in the marine mussel, Mytilus californianus. Environ Sci Technol 40:5580-5585
Su YH, Zhu YG (2006) Bioconcentration of atrazine and chlorophenols into roots and shoots of rice seedlings. Environ Pollut 139:32-39

Su YH, Zhu YG, Du X (2005) Co-uptake of atrazine and mercury by rice seedlings from water. Pestic Biochem Physiol 82:226-232

Sun H, Gerecke AC, Giger W, Alder AC (2011) Long-chain perfluorinated chemicals in digested sewage sledges in Switzerland. Environ Pollut 159:654-662

Thompson JG, McNaughton C, Gasparrini B, McGowan LT, Tervit HR (2000) Effect of inhibitors and uncouplers of oxidative phosphorylation during compaction and blastulation of bovine embryos cultured in vitro. J Reprod Fert 118:47-55

Trapp S, Franco A, Mackay D (2010) Activity-based concept for transport and partitioning of ionizing organics. Environ Sci Technol 44:6123-6129

Wang X, Ma LQ, Rathinasabapathi B, Cai Y, Liu YG, Zeng GM (2011) Mechanisms of efficient arsenite uptake by arsenic hyperaccumulator Pteris vittata. Environ Sci Technol 45:9719-9725

Washington JW, Yoo H, Ellington JJ, Jenkins TM, Libelo EL (2010) Concentrations, distribution, and persistence of perfluoroalkylates in sludge-applied soils near Decatur, Alabama, USA. Environ Sci Technol 44:8390-8396

Wen B, Huang RX, Wang P, Zhou YP, Shan XQ, Zhang SZ (2011) Effect of complexation on the accumulation and elimination kinetics of cadmium and ciprofloxacin in the earthworm Eisenia fetida. Environ Sci Technol 45:4339-4345

Yamashita N, Taniyasu S, Petrick G, Gamo T, Lam PKS, Kannan K (2011) Perfluorinated acids as novel chemical tracers of global circulation of ocean waters. Chemoshere 70:1247-1255

Yang CH, Glover KP, Han X (2010) Characterization of cellular uptake of perfluorooctanoate via organic aniontransporting polypeptide $1 \mathrm{~A} 2$, organic anion transporter 4, and urate transporter 1 for their potential roles in mediating human renal reabsorption of perfluorocarboxylates. Toxicol Sci 117:294-302

Yoo H, Washington JW, Ellington JJ, Jenkins TM, Neill MP (2010) Concentrations, distribution, and persistence of fluorotelomer alcohols in sludge-applied soils near Decatur, Alabama, USA. Environ Sci Technol 44:8397-8402

Yoo H, Washington JW, Jenkins TM, Ellington JJ (2011) Quantitative determination of perfluorochemicals and fluorotelomer alcohols in plants from biosolid-amended fields using LC/MS/MS and GC/MS. Environ Sci Technol 45:7985-7990

You JF, Hou NN, Xu MY, Zhang HM, Yang ZM (2010) Citrate transporters play an important role in regulating aluminuminduced citrate secretion in Glycine max. Biol Plant 54:766-768

Zhan XH, Ma HL, Zhou LX, Liang JR, Jiang TH, Xu GH (2010) Accumulation of phenanthrene by roots of intact wheat (Triticum acstivnm L.) seedlings: passive or active uptake? BMC Plant Biol 10:52-59

Zhao H, Chen C, Zhang X, Chen J, Quan X (2011) Phytotoxicity of PFOS and PFOA to Brassic chinensis in different Chinese soils. Ecotox Environ Safe 74:1343-1347 